\title{
Taking a confident leap into uncertainty
}

\author{
Melina Schuh did her PhD at the European Molecular Biology Laboratory with Jan Ellenberg. She became group \\ leader at the Medical Research Council Laboratory of Molecular Biology in Cambridge, UK, in 2009, and was \\ appointed Director at the Max Planck Institute for Biophysical Chemistry in Göttingen, Germany, in 2016.
}

\section{Melina Schuh}

\begin{abstract}
$\mathrm{t}$ was a short e-mail that changed my life. It came from the Medical Research Council Laboratory of Molecular Biology (LMB) while I was writing my $\mathrm{PhD}$ thesis. It said that the Cell Biology Division at the LMB was searching for a new group leader. They had seen our recent Cell paper on spindle assembly in mouse oocytes and thought that this was an interesting research area. Would I consider applying to the advert? The application deadline was about a week away. I still remember how excited I was after reading this e-mail. What if they offered me the position? Would I really want to become a group leader straight after my PhD? Would I even be able to write a decent research proposal within one week?

I decided to try it. I wrote the proposal,
\end{abstract} and was invited for an interview. The visit went well, and a few days later I received another e-mail, this time with an offer. Did I think twice about accepting the position? No. I believe in taking opportunities as they come along, and this was a great offer. So I accepted it, and at the end of 2008 I moved to Cambridge. The lab space at the LMB was tiny, the building itself had seen better days, but I noticed very soon that all this would not matter. What did matter was the inspiring research all around me, and the supportive environment that I found there. Matthew Freeman and Sean Munro were heads of the Cell Biology Division, and they were very supportive and valued my research.

This support was very helpful when I started my group. Suddenly, I had to make every decision on my own, whether it was about recruitment, research projects or dealing with competition. I truly enjoyed this new role, but I also realised that you have to grow up quickly when you start your own lab. Following the LMB's philosophy, I started with a very small group - a $\mathrm{PhD}$ student, a postdoc and myself - so prioritizing projects was of the utmost importance. This was a challenge though. I generated lists in which I scored projects for factors such as impact, competition, probability of success and potential for follow-up work. I calculated weighted scores

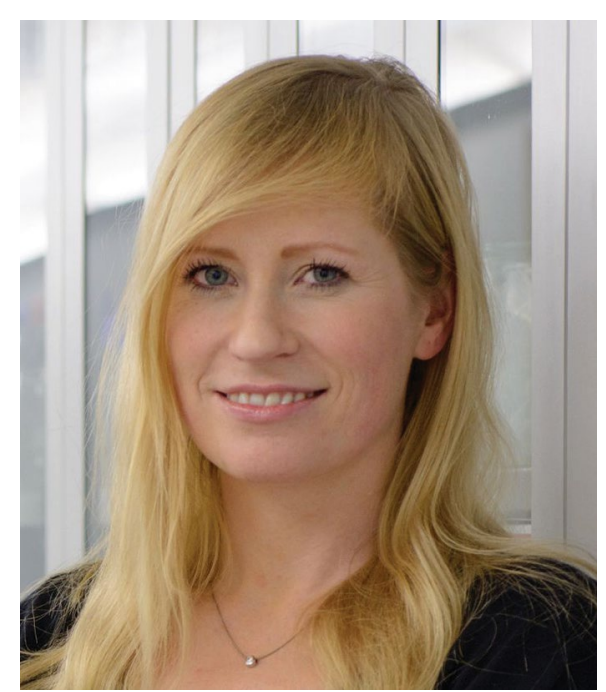

Credit: Irene Böttcher-Gajewski / MPI BPC

for each one, only to then find out that there were still too many interesting projects and that, to some degree, I would have to get used to making decisions without being able to predict long-term outcomes. I comforted myself with the thought that if I ended up making all the wrong decisions, then I would found a start-up in Berlin, following the entrepreneurial footsteps of my father. So I kept a secret list of start-up ideas in my bedside drawer. Luckily I did not have to go back to this list as our research started to take off. We carried out many exciting projects, including the first studies of chromosome segregation in live human oocytes. This was a collaboration with Bourn Hall Clinic, the world's first in vitro fertilization (IVF) clinic that was founded by Bob Edwards and Patrick Steptoe, the pioneers of IVF in humans. We also performed a large scale screen for meiotic genes in mammals, and developed TrimAway, a method for acute degradation of endogenous, unmodified proteins.

On top of all the excitement, my husband and I decided to start a family. Working on reproduction you might hear your own biological clock ticking a little louder. A few people did ask me if I had thought about this properly; not having tenure yet and with my husband being in Germany, shouldn't I wait a little longer instead of having children so soon after starting my own group? I decided that having children was too important and that I would find a way to make it work. I had two children as a group leader in Cambridge, with my husband working in Germany and flying in for the weekend, and one more child after I had moved back to Germany to become Director at the Max Planck Institute for Biophysical Chemistry. I was on maternity leave for 3-4 months each time, and I loved this wonderful experience. But I think life has never been as busy as it was during this time - work does not stop, e-mails still need answering, grant applications and paper revisions need submitting, and people in the lab still need advice; and then there is this little miracle with whom you want to spend as much time as possible. I discovered that I could work on my laptop if the baby was sleeping tucked around my belly on a nursing pillow. Not ideal, but as a scientist and mother I realised very soon that you have to make compromises.

On returning to work my life certainly was not back to my old 'normal'. For the following years, I had to fight with constant sleep-deprivation, stomach bugs alternating with sore throats, and the feeling of having too little time for everything. But here I am, a very happy me, truly grateful for everything I have, and I would not change a thing. To those wondering whether you can do this as well, I would encourage you to be confident. It is not easy, and things will not always run smoothly, but you should dare to grasp opportunities as they arise and to make your own decisions. And if things do not work out... a start-up in Berlin may be an attractive backup option.

\section{Melina Schuh}

Max Planck Institute for Biophysical Chemistry,

Göttingen, Germany.

e-mail:melina.schuh@mpibpc.mpg.de

Published online: 28 August 2018

https://doi.org/10.1038/s41556-018-0177-1

Competing interests

The author declares no competing interests. 